Article

\title{
Positive Programmed Cell Death-Ligand 1 Expression Predicts Poor Treatment Outcomes in Esophageal Squamous Cell Carcinoma Patients Receiving Neoadjuvant Chemoradiotherapy
}

\author{
Wan-Ting Huang ${ }^{1,2}{ }^{-}$, Hung-I Lu ${ }^{3}$, Yu-Ming Wang ${ }^{4}$, Yen-Hao Chen ${ }^{5}$, Chien-Ming Lo ${ }^{3}$, \\ Wei-Che Lin ${ }^{6}$, Ya-Chun Lan ${ }^{5}$, Ling-Huei Tseng ${ }^{5}$ and Shau-Hsuan $\mathrm{Li}^{5, *}$ \\ 1 Department of Pathology, Kaohsiung Chang Gung Memorial Hospital and Chang Gung University College \\ of Medicine, Kaohsiung 83301, Taiwan; huangwanting5@gmail.com \\ 2 Affiliation 2; Department of Medical Laboratory Sciences and Biotechnology, Fooyin University, \\ Kaohsiung 83102, Taiwan \\ 3 Department of Thoracic and Cardiovascular Surgery, Kaohsiung Chang Gung Memorial Hospital and \\ Chang Gung University College of Medicine, Kaohsiung 83301, Taiwan; luhungi@yahoo.com.tw (H.-I.L.); \\ t123207424@cgmh.org.tw (C.-M.L.) \\ 4 Department of Radiation Oncology, Kaohsiung Chang Gung Memorial Hospital and Chang Gung \\ University College of Medicine, Kaohsiung 83301, Taiwan; scorpion@cgmh.org.tw \\ 5 Department of Hematology-Oncology, Kaohsiung Chang Gung Memorial Hospital and Chang Gung \\ University College of Medicine, Kaohsiung 83301, Taiwan; alex2999@cgmh.org.tw (Y.-H.C.); \\ amylan1226@gmail.com (Y.-C.L.); libbycatblue@gmail.com (L.-H.T.) \\ 6 Department of Diagnostic Radiology, Kaohsiung Chang Gung Memorial Hospital and Chang Gung \\ University College of Medicine, Kaohsiung 83301, Taiwan; u64lin@yahoo.com.tw \\ * Correspondence: lee.a0928@msa.hinet.net; Tel.: +886-7-7317123 (ext. 8303); Fax: +886-7-7322402
}

Received: 10 October 2019; Accepted: 31 October 2019; Published: 3 November 2019

\begin{abstract}
Background: Programmed cell death-ligand 1 (PD-L1) is present in a subgroup of cancer patients who may be favorable targets for immune checkpoint inhibitor therapies. However, the significance of the PD-L1 expression in esophageal squamous cell carcinoma (ESCC) patients receiving neoadjuvant chemoradiotherapy remains unclear. Methods: By means of PD-L1 immunohistochemistry 22C3 pharmDx assay, we evaluate the PD-L1 expression and its association with clinical outcome in 107 ESCC patients receiving neoadjuvant chemoradiotherapy. Results: Patients with positive PD-L1 expression have significantly lower pathological complete response rates $(13 \%$ versus $32 \% ; p=0.036)$ than those with negative PD-L1 expression. Univariate survival analysis found that positive PD-L1 expression were correlated with poor overall survival $(p=0.004)$ and inferior disease-free survival $(p<0.001)$. In a multivariate analysis, positive PD-L1 expression was independently associated with the absence of a pathologically complete response $(p=0.044$, hazard ratio: 3.542), worse overall survival ( $p=0.006$, hazard ratio: 2.017), and inferior disease-free survival $(p<0.001$, hazard ratio: 2.516). Conclusions: For patients with ESCC receiving neoadjuvant chemoradiotherapy, positive PD-L1 expression independently predicts the poor chemoradiotherapy response and worse treatment outcome. Thus, our data suggests that PD-L1 may be an influential biomarker for prognostic classification and for immune checkpoint inhibitor therapies in ESCC patients receiving neoadjuvant chemoradiotherapy.
\end{abstract}

Keywords: esophageal cancer; squamous cell carcinoma; PD-L1; chemoradiotherapy; immunotherapy 


\section{Introduction}

In 2018, esophageal cancer was the sixth most common cause of cancer-related death worldwide [1]. In Asia, squamous cell carcinoma is the most prevalent histology of esophageal cancer. At diagnosis, patients with esophageal squamous cell carcinoma (ESCC) usually present with the advanced disease. The standard treatment modality for ESCC is esophagectomy. However, previous research has shown that the five-year overall survival rate of patients with advanced ESCC after receiving esophagectomy alone is only $20-30 \%$ [2-5]. Neoadjuvant chemoradiotherapy has been proposed for patients with advanced ESCC to reduce the primary tumor size and dispose of the micrometastases. Recent randomized trials and meta-analysis have revealed that neoadjuvant chemoradiotherapy followed by esophagectomy has a significant survival benefit compared to esophagectomy alone [6-10]. In particular, patients who achieved a pathological complete response following neoadjuvant chemoradiotherapy had improved survival odds than those who did not [11,12]. However, following neoadjuvant chemoradiotherapy, esophagectomy specimens show that only $20-40 \%$ patients can achieve pathological complete response $[7,13,14]$, indicating that a large portion of patients do not respond to chemoradiotherapy. Furthermore, patients receiving neoadjuvant chemoradiotherapy followed by esophagectomy had higher morbidity and mortality rates postoperatively than those receiving esophagectomy alone [15]. Therefore, a biomarker is helpful to forecast the chemoradiotherapy response and its presence may shed light on novel target development.

The immune checkpoint proteins (programmed as cell death 1 (PD-1) receptor) and its ligand (programmed cell death ligand 1 (PD-L1)) are involved in the immune escape of cancer cells [16]. PD-L1 expressed on cancer cells binds to PD-1 receptor on T cells, which leads to $\mathrm{T}$ cell inactivation and exhaustion. This hampers cytokine production and causes $\mathrm{T}$ cell apoptosis. Cumulatively, these effects contribute to the growth of cancer cells $[17,18]$. Several studies have reported that PD-L1 overexpression predicts anticancer therapy resistances and poor treatment outcomes [19-21]. In addition, the use of PD-1/PD-L1 axis inhibitors in recent clinical trials had the meaningful activity and overall survival benefit in several types of cancers, including esophageal cancer [22-25]. Studies have also demonstrated that PD-L1 protein expression on the surface of cancer cells is associated with enhanced responses to PD-1/PD-L1 axis inhibitors [23,26]. However, the significance of PD-L1 expression in patients with ESCC after receiving neoadjuvant chemoradiotherapy followed by esophagectomy has not been investigated. Although biopsy specimens before treatment are often very small and show significant difference, they are the only tumor tissue samples for predicting clinical outcome in ESCC patients that have received neoadjuvant chemoradiotherapy. Therefore, we performed PD-L1 immunohistochemistry on pre-treatment biopsy specimens obtained from patients with advanced ESCC receiving neoadjuvant chemoradiotherapy followed by esophagectomy and then correlated the immunohistochemical results with treatment outcomes.

\section{Materials and Methods}

\subsection{Patient and Tumor Materials}

Between 1999 and 2013, ESCC patients that underwent neoadjuvant chemoradiotherapy followed by esophagectomy at Chang Gung Memorial Hospital and the Kaohsiung medical center were retrospectively analyzed. Patients without biopsy specimens before neoadjuvant chemoradiothrapy for immunohistochemistry were not allowed. The institutional review board of the Chang Gung Memorial Hospital approved the present study. The seventh American Joint Committee on Cancer (AJCC) staging system was used for clinical staging. The clinical staging was determined according to image examinations including a computed tomography (CT) scan of the abdomen and chest, endoscopic ultrasound (EUS), and/or positron emission tomography (PET) scan. The protocol of neoadjuvant chemoradiotherapy followed by esophagectomy was previously described [14,27]. Overall survival (OS) was computed from diagnosis date until the death date or the last follow-up. Disease-free survival (DFS) was calculated from the esophagectomy date until death due to any cause without 
recurrence evidence or date of recurrence. Ultimately, 107 ESCC patients who received neoadjuvant chemoradiotherapy followed by esophagectomy were enrolled for further analysis.

\subsection{Immunohistochemistry (IHC)}

The specimens were fixed in buffered formalin and embedded in paraffin. The IHC was carried out using standard reagents and techniques on a Dako Autostainer Link 48 platform (Agilent Technologies, Santa Clara, CA, USA) and EnVision FLEX visualization system (Agilent Technologies, citySanta Clara, CA, countryUSA). An automated IHC staining protocol of the PD-L1 IHC 22C3 pharmDx assay (Dako, Carpinteria, CA, USA) was verified with positive and negative controls used per manufacturer instructions. Briefly, in the PT Link (Dako PT100), deparaffinization, rehydration, and target antigen retrieval were performed through a three in one process. Then, specimens were incubated with the monocloncal mouse control IgG antibody (negative control) or anti-human PD-L1 monoclonal mouse antibody (clone 22C3), then with an anti-mouse linker antibody specific to the host species of the primary antibody, and then with a ready-to-use visualization reagent consisting of goat secondary antibody molecules and horseradish peroxidase molecules coupled with dextran. The enzymatic conversion of the subsequently added 3,3'-diaminobenzidine tetrahydrochloride (DAB) chromogen with color modification using a DAB enhancer resulted in precipitation of a visible reaction product at the site of antigen. The sections were then counterstained with hematoxylin and interpreted by a pathologist using a light microscope.

To determine the expression of PD-L1 protein, total viable tumor cells were evaluated and only tumors containing at least 100 viable tumor cells were scored. The positive staining was assessed in the context of non-specific background with 0 specific staining and $<1+$ intensity in the negative control reagent slide. The positivity of PD-L1 was represented as the complete circumferential or partial cell membrane staining of viable cancer cells. Tumor proportion score (TPS) was defined as the percentage of positive tumor cells over total tumor cells in the denominator. Tumor-associated immune cells or tumor cells with cytoplasmic staining were excluded from the scoring. Positive PD-L1 expression was defined as TPS $>1 \%$.

\subsection{Statistical Analysis}

Statistical analysis was performed using the SPSS 17 software package (manufactureIBM Corp., cityArmonk, NY, countryUSA). We used the chi-square test to compare the categorical data between the two groups. Logistic regression was used for the multivariate analysis of the pathological complete response. For univariate survival analysis in these patients, the Kaplan-Meier method was performed to plot the figures of OS and DFS. The difference between the two groups was evaluated by the log rank test. For multivariate survival analysis, the cox proportional hazards regression model was used. For every analysis, two-sided tests of significance were performed and the $p$ value $<0.05$ was considered as significant.

\section{Results}

\subsection{Patient Clinicopathological Characteristics}

Table 1 shows the clinicopathological characteristics of these 107 patients. The median age of was 52 years (range: $37-77$ years). The stage was revealed to be AJCC seventh stage II in 21 (20\%) patients and AJCC seventh stage III in $86(80 \%)$ patients. Meanwhile, the T classifications were T2 in $11(10 \%)$ patients, T3 in $46(43 \%)$ patients, and T4 in $50(47 \%)$ patients. Additionally, $22(21 \%)$ patients had N0 status, $36(34 \%)$ patients had N1 status, $35(33 \%)$ patients had N2 status, and $14(13 \%)$ patients had N3 status. The locations of the primary tumor were as follows: upper esophagus in $20(19 \%)$ patients, the middle esophagus in $43(40 \%)$ patients, and the lower esophagus in $44(41 \%)$ patients. In terms of a histologic grade, $22(21 \%)$ patients were diagnosed with a grade 1 lesion, $58(54 \%)$ patients were diagnosed with a grade 2 lesion, and $27(25 \%)$ patients were diagnosed with a grade 3 lesion. 
Among these 107 patients receiving neoadjuvant chemoradiotherapy followed by esophagectomy, $28(26 \%)$ patients achieved pathological complete response. The three-year OS and DFS rates of these 107 patients were $37 \%$ and $32 \%$, respectively.

Table 1. Clinicopathologic features of 107 patients with locally advanced esophageal squamous cell carcinoma who received preoperative chemoradiotherapy.

\begin{tabular}{|c|c|}
\hline Parameters & No. of Cases (Percentage) \\
\hline \multicolumn{2}{|l|}{ Age (years) (mean: 53.6, median: 52, range $37-77$ ) } \\
\hline 50 & $40(37 \%)$ \\
\hline $50 \leq$ Age 60 & $36(34 \%)$ \\
\hline $60 \leq$ Age 70 & $27(25 \%)$ \\
\hline $70 \leq$ Age & $4(4 \%)$ \\
\hline \multicolumn{2}{|c|}{ Clinical seventh American Joint Committee on Cancer (AJCC) stage } \\
\hline II & $21(20 \%)$ \\
\hline III & $86(80 \%)$ \\
\hline \multicolumn{2}{|l|}{ Clinical T classification } \\
\hline $\mathrm{T} 2$ & $11(10 \%)$ \\
\hline T3 & $46(43 \%)$ \\
\hline $\mathrm{T} 4$ & $50(47 \%)$ \\
\hline \multicolumn{2}{|l|}{ Clinical N classification } \\
\hline N0 & $22(21 \%)$ \\
\hline N1 & $36(34 \%)$ \\
\hline N2 & $35(33 \%)$ \\
\hline N3 & $14(13 \%)$ \\
\hline \multicolumn{2}{|l|}{ Histologic grade (Tumor differentiation) } \\
\hline Grade 1 (Well differentiated) & $22(21 \%)$ \\
\hline Grade 2 (Moderately differentiated) & $58(54 \%)$ \\
\hline Grade 3 (poorly differentiated, undifferentiated) & $27(25 \%)$ \\
\hline \multicolumn{2}{|l|}{ Primary tumor location } \\
\hline Upper & $20(19 \%)$ \\
\hline Middle & $43(40 \%)$ \\
\hline Lower & $44(41 \%)$ \\
\hline \multicolumn{2}{|l|}{ PD-L1 expression } \\
\hline Negative & $75(70 \%)$ \\
\hline $\begin{array}{c}\text { Positive } \\
\text { pCR }\end{array}$ & $32(30 \%)$ \\
\hline Absent & $79(74 \%)$ \\
\hline Present & $28(26 \%)$ \\
\hline
\end{tabular}

PD-L1, programmed death-ligand 1; $\mathrm{pCR}$, pathological complete response.

As shown in Table 1, $75(70 \%)$ and $32(30 \%)$ patients were negative and positive for PD-L1 expression, respectively (Figure 1). There were no significant correlations between PD-L1 expression with histologic grade, primary tumor location, age, clinical T classification, clinical $\mathrm{N}$ classification, and clinical AJCC seventh staging (Table 2) 


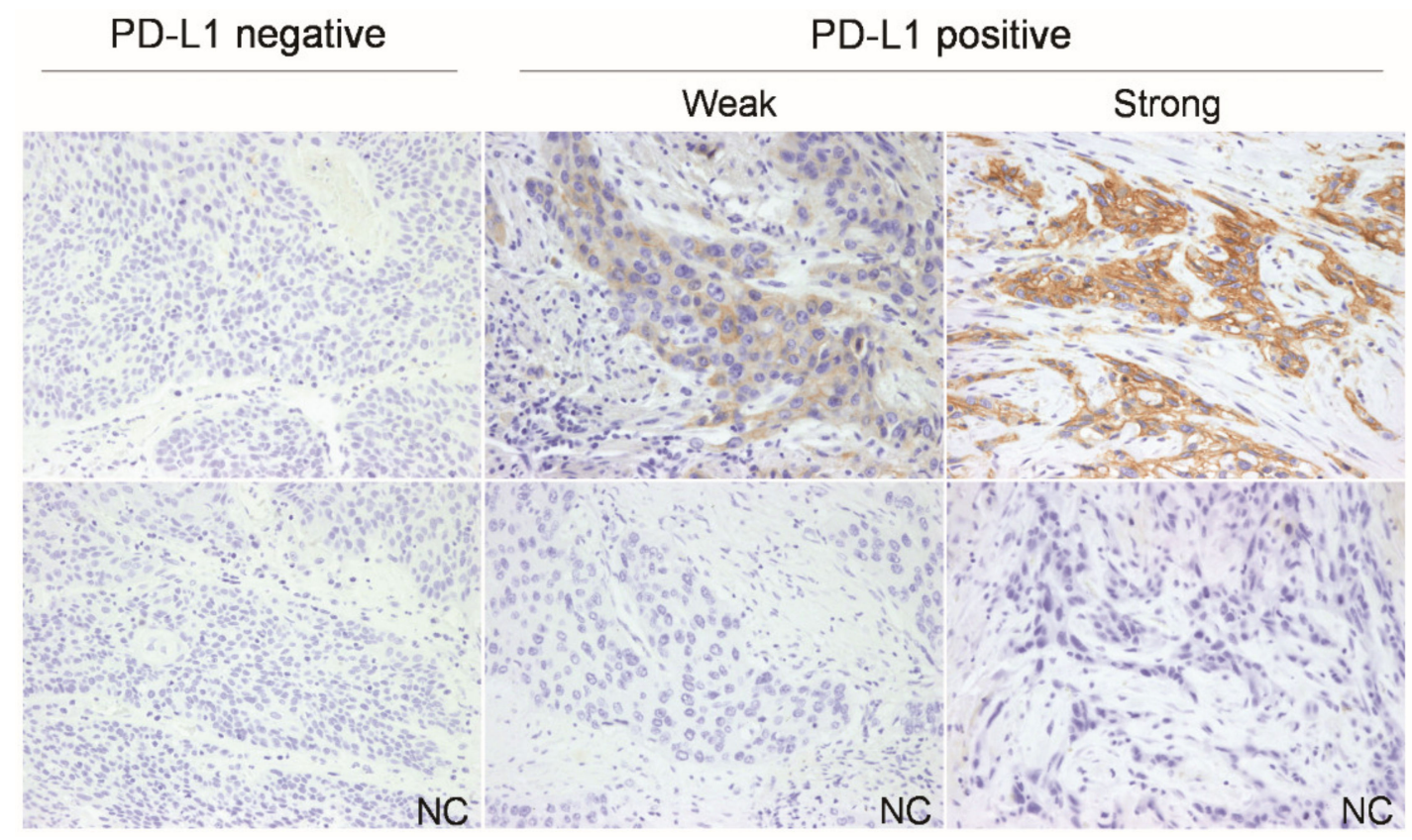

Figure 1. Representative photographs of PD-L1 immunostaining in esophageal squamous cell carcinoma. The positive staining was assessed against the negative control staining (NC) (original magnification 200x). PD-L1, programmed death-ligand 1.

Table 2. Associations between PD-L1 expression and clinicopathologic parameters.

\begin{tabular}{|c|c|c|c|c|}
\hline \multicolumn{2}{|l|}{ Parameters } & \multicolumn{3}{|c|}{ PD-L1 Expression } \\
\hline \multirow{3}{*}{ Age } & & Negative & Positive & $p$ value \\
\hline & $\leq 52$ years old & 40 & 15 & 0.54 \\
\hline & 52 years old & 35 & 17 & \\
\hline \multirow{2}{*}{ Clinical seventh AJCC stage } & II & 15 & 6 & 0.88 \\
\hline & III & 60 & 26 & \\
\hline \multirow{2}{*}{ Clinical T classification } & $\mathrm{T} 2 / 3$ & 39 & 18 & 0.69 \\
\hline & $\mathrm{T} 4$ & 36 & 14 & \\
\hline \multirow{2}{*}{ Clinical $\mathrm{N}$ classification } & N0 & 18 & 4 & 0.18 \\
\hline & $\mathrm{N} 1 / 2 / 3$ & 57 & 28 & \\
\hline \multirow{2}{*}{ Clinical N classification } & N0/1 & 40 & 18 & 0.78 \\
\hline & $\mathrm{N} 2 / 3$ & 35 & 14 & \\
\hline \multirow{2}{*}{ Histologic grade } & Grade $1 / 2$ & 56 & 24 & 0.97 \\
\hline & Grade 3 & 19 & 8 & \\
\hline \multirow{2}{*}{ Histologic grade } & Grade 1 & 18 & 4 & 0.18 \\
\hline & Grade $2 / 3$ & 57 & 28 & \\
\hline \multirow{2}{*}{ Primary tumor location } & Upper/Middle & 44 & 19 & 0.95 \\
\hline & Lower & 31 & 13 & \\
\hline
\end{tabular}

PD-L1, programmed death-ligand $1 . \mathrm{x}^{2}$ test was used for statistical analysis.

\subsection{Associations between Pathological Complete Respoznse with Clinicopathological Characteristics}

Table 3 revealed the correlation between pathological complete responses with clinicopathological characteristics. We observed that positive PD-L1 expression $(p=0.036)$ and clinical T classification, T4 $(p=0.025)$ were significantly associated with the absence of pathological complete response. The multivariate analysis demonstrated that positive PD-L1 expression $(p=0.044$, hazard ratio: 3.542 , $95 \%$ confidence interval: $1.033-12.152)$ and clinical T classification, T4 $(p=0.047$, hazard ratio: $3.225,95 \%$ confidence interval: 1.016-10.231), were independently associated with the absence of a pathologically complete response. 
Table 3. Associations between a pathologically complete response and clinicopathologic parameters.

\begin{tabular}{|c|c|c|c|c|}
\hline \multicolumn{2}{|l|}{ Parameters } & \multicolumn{3}{|c|}{ Pathological Complete Response } \\
\hline \multirow{3}{*}{ Age } & & Present & Absent & $p$ value \\
\hline & $\leq 52$ years old & 11 & 44 & 0.14 \\
\hline & 52 years old & 17 & 35 & \\
\hline \multirow{2}{*}{ Clinical seventh AJCC stage } & II & 8 & 13 & 0.17 \\
\hline & III & 20 & 66 & \\
\hline \multirow{2}{*}{ Clinical T classification } & $\mathrm{T} 2 / 3$ & 20 & 37 & $0.025^{*}$ \\
\hline & $\mathrm{T} 4$ & 8 & 42 & \\
\hline \multirow{2}{*}{ Clinical $\mathrm{N}$ classification } & N0 & 9 & 13 & 0.078 \\
\hline & $\mathrm{N} 1 / 2 / 3$ & 19 & 66 & \\
\hline \multirow{2}{*}{ Clinical $\mathrm{N}$ classification } & N0/1 & 17 & 41 & 0.42 \\
\hline & $\mathrm{N} 2 / 3$ & 11 & 38 & \\
\hline \multirow{2}{*}{ Histologic grade } & Grade $1 / 2$ & 19 & 61 & 0.87 \\
\hline & Grade 3 & 6 & 21 & \\
\hline \multirow{2}{*}{ Histologic grade } & Grade 1 & 8 & 14 & 0.22 \\
\hline & Grade 2/3 & 20 & 65 & \\
\hline \multirow{2}{*}{ Primary tumor location } & Upper/Middle & 12 & 51 & 0.21 \\
\hline & Lower & 13 & 31 & \\
\hline \multirow{2}{*}{ PD-L1 expression } & Negative & 24 & 51 & $0.036^{*}$ \\
\hline & Positive & 4 & 28 & \\
\hline
\end{tabular}

PD-L1, programmed death-ligand 1. * Statistically significant. $x^{2}$ test or Fisher's exact test was used for statistical analysis.

\subsection{Associations between Patient Survival with Clinicopathological Characteristics}

Table 4 shows the association between OS and DFS with clinicopathological characteristics and PD-L1 expression. We found that positive PD-L1 expression ( $p=0.004$; Figure 2A), clinical $\mathrm{T}$ classification, $\mathrm{T} 4(p=0.015)$, and clinical $\mathrm{N}$ classification, $\mathrm{N} 2 / 3(p=0.025)$ were correlated with inferior OS significantly at univariate level. Besides, univariate analysis also revealed that positive PD-L1 expression ( $p<0.001$; Figure 2B), clinical T classification, T4 $(p=0.006)$, and clinical N classification, N2/3 $(p=0.044)$ were significantly correlated with poor DFS. In a multivariate analysis, positive PD-L1 expression ( $p=0.006$, hazard ratio: $2.017,95 \%$ confidence interval: $1.223-3.326$ ) and clinical T classification, T4 ( $p=0.022$, hazard ratio: $1.910,95 \%$ confidence interval: $1.097-3.325$ ), were independently poor prognosticators for inferior OS. Meanwhile, positive PD-L1 expression $(p<0.001$, hazard ratio: $2.516,95 \%$ confidence interval: $1.537-4.120)$ and clinical T classification, T4 ( $p=0.03$, hazard ratio: $1.857,95 \%$ confidence interval: $1.060-3.252)$, were independently associated with worse DFS. The three-year OS rates were $47 \%$ in patients with negative PD-L1 expression, and 16\% in patients with positive PD-L1 expression. The three-year DFS rates were $43 \%$ in patients with negative PD-L1 expression, and 6\% in patients with positive PD-L1 expression. 
Table 4. Results of univariate log-rank analysis of prognostic factors for overall survival and disease-free survival in 107 patients with locally advanced esophageal squamous cell carcinoma who received preoperative chemoradiotherapy.

\begin{tabular}{|c|c|c|c|c|c|}
\hline \multirow{2}{*}{ Factors } & \multirow{2}{*}{ No. of Patients } & \multicolumn{2}{|c|}{ Overall Survival (OS) } & \multicolumn{2}{|c|}{ Disease-Free Survival (DFS) } \\
\hline & & 3-Year OS Rate (\%) & $p$ Value & 3-Year DFS Rate (\%) & $p$ Value \\
\hline \multicolumn{6}{|l|}{ Age } \\
\hline$\leq 52$ years old & 55 & $35 \%$ & 0.51 & $29 \%$ & 0.86 \\
\hline 52 years old & 52 & $40 \%$ & & $35 \%$ & \\
\hline \multicolumn{6}{|c|}{$\begin{array}{c}\text { Clinical seventh AJCC } \\
\text { stage }\end{array}$} \\
\hline II & 21 & $52 \%$ & 0.14 & $52 \%$ & 0.084 \\
\hline III & 86 & $34 \%$ & & $27 \%$ & \\
\hline \multicolumn{6}{|c|}{ Clinical $\mathrm{T}$ classification } \\
\hline $\mathrm{T} 2 / 3$ & 57 & $49 \%$ & $0.015^{*}$ & $42 \%$ & $0.006^{*}$ \\
\hline $\mathrm{T} 4$ & 50 & $24 \%$ & & $20 \%$ & \\
\hline \multicolumn{6}{|c|}{ Clinical N classification } \\
\hline NO & 22 & $55 \%$ & 0.10 & $55 \%$ & $0.046^{*}$ \\
\hline $\mathrm{N} 1 / 2 / 3$ & 85 & $33 \%$ & & $26 \%$ & \\
\hline \multicolumn{6}{|c|}{ Clinical N classification } \\
\hline $\mathrm{N} 0 / 1$ & 58 & $47 \%$ & $0.025^{*}$ & $38 \%$ & $0.044^{*}$ \\
\hline $\mathrm{N} 2 / 3$ & 49 & $27 \%$ & & $25 \%$ & \\
\hline \multicolumn{6}{|l|}{ Histologic grade } \\
\hline Grade 1/2 & 80 & $39 \%$ & 0.18 & $33 \%$ & 0.82 \\
\hline Grade 3 & 27 & $33 \%$ & & $30 \%$ & \\
\hline \multicolumn{6}{|l|}{ Histologic grade } \\
\hline Grade 1 & 22 & $50 \%$ & 0.17 & $50 \%$ & 0.24 \\
\hline Grade $2 / 3$ & 85 & $34 \%$ & & $27 \%$ & \\
\hline \multicolumn{6}{|c|}{ Primary tumor location } \\
\hline Upper/Middle & 63 & $38 \%$ & 0.89 & $30 \%$ & 0.75 \\
\hline Lower & 44 & $36 \%$ & & $34 \%$ & \\
\hline \multicolumn{6}{|l|}{ PD-L1 expression } \\
\hline Negative & 75 & $47 \%$ & $0.004^{*}$ & $43 \%$ & $0.001^{*}$ \\
\hline Positive & 32 & $16 \%$ & & $6 \%$ & \\
\hline
\end{tabular}

PD-L1, programmed death-ligand 1. *Statistically significant. 
A

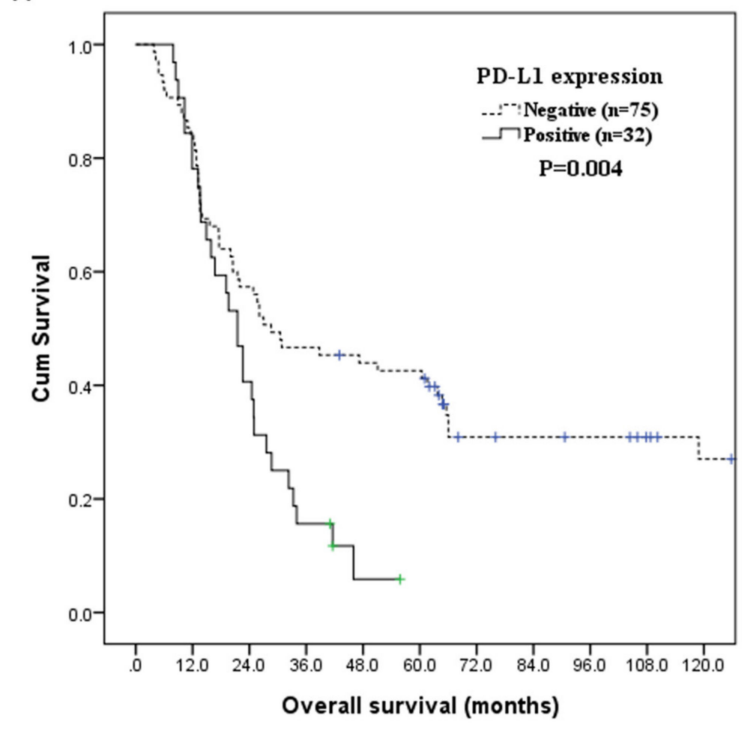

B

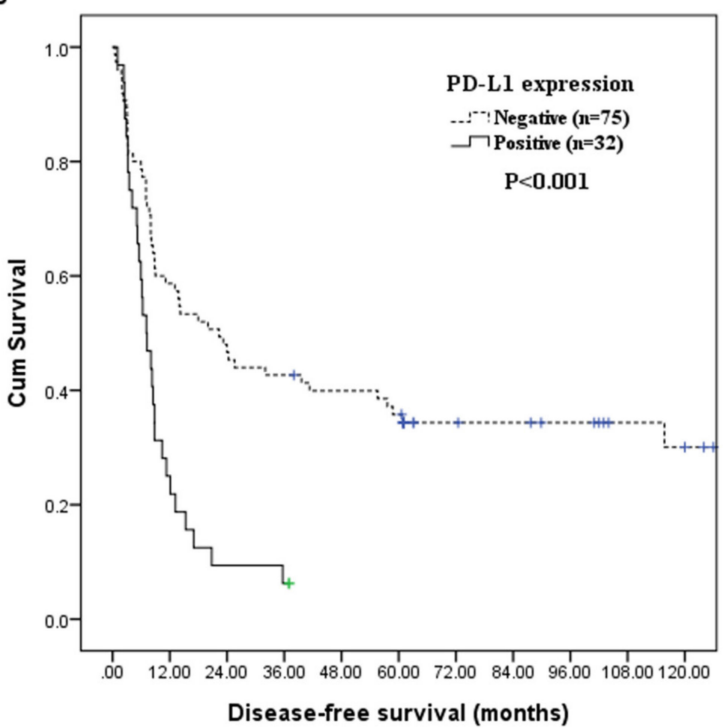

Figure 2. (A) Overall survival according to PD-L1 expression. (B) Disease-free survival according to PD-L1 expression. PD-L1, programmed death-ligand 1.

\section{Discussion}

Previous studies [26,28] have described that positive PD-L1 expression is correlated with worse prognosis in numerous human cancers and also suggested that such expression could serve as a biomarker which predicts the response to anti-PD-1/PD-L1 therapies. However, the significance of PD-L1 expression in patients with ESCC receiving neoadjuvant chemoradiotherapy followed by esophagectomy remain largely undefined. Therefore, we conducted the current study in order to determine the significance of PD-L1 expression in ESCC patients who underwent neoadjuvant chemoradiotherapy followed by esophagectomy.

In the present study, positive PD-L1 expression was noted in $32(30 \%)$ of 107 patients with ESCC. Hatogai et al. [29] reported that positive PD-L1 expression was noted in 67 (23.4\%) of 286 patients with ESCC receiving curative surgical resection. Meanwhile, a recent meta-analysis [30] showed that positive PD-L1 expression was observed in $559(41.4 \%)$ of 1350 patients with ESCC. The discrepancy between these studies may have resulted from differences in the PD-L1 antibodies and IHC assessment methods used. 
In our study, we did not observe a significant correlation between histologic grades with pathologically complete responses, despite a previous study by Tamaoki et al. [31] that reported a single-minded 2 (SIM2) increased chemoradiotherapy sensitivity through tumor differentiation in ESCC. However, we found that positive PD-L1 expression was significantly associated with the absence of pathological complete response. We observed that pathologically complete responses after neoadjuvant chemoradiotherapy was noted in $24(32 \%)$ of the 75 patients with negative PD-L1 expression. However, $4(13 \%)$ of the 32 patients with positive PD-L1 expressions achieved a pathologically complete response. For patients with locally advanced ESCC, multimodality treatment including definitive chemoradiotherapy or neoadjuvant chemoradiotherapy followed by esophagectomy has been commonly used. The ability to distinguish responders from non-responders could provide more suitable multimodality treatment options.

Our study revealed that a positive PD-L1 expression is an independent prognosticator in patients with advanced ESCC treated with preoperative chemoradiotherapy. Kudo et al. [25] showed that the use of the anti-PD-1 antibody, nivolumab, in 65 chemotherapy-refractory ESCC patients showed promising activity, with a $17 \%$ objective response rate and a manageable safety profile. Tanaka et al. [32] first reported that many interferon-gamma-inducible genes including PD-L1 and cytotoxic T-lymphocyte markers such as perforin (PRF1) and granzyme B (GZMB) were activated by chemoradiotherapy in ESCC. Lim et al. [33] acquired 19 paired ESCC tumor tissues before and after preoperative chemoradiotherapy and found that PD-L1 expression in ESCC cells increased after preoperative chemoradiotherapy. The recent phase III PACIFIC study [34] reported that after chemoradiotherapy, the administration of the anti-PD-L1 antibody, durvalumab, can ameliorate progression-free survival in non-small-cell lung cancer patients with unresectable stage III disease. Taken together, these previous studies and our findings highlight the potential for a combination of anti-PD-1/PD-L1 therapy and chemoradiotherapy in patients with advanced ESCC.

The present study has limitations. The patient number in our study is relatively small. Our analysis was retrospective. Furthermore, we did not evaluate PD-L1 expression in immune cells because some of the biopsy specimens were too small to have enough cells evaluated. Besides, biopsy specimens are too small to show significant difference. For clinical use, the cut-off value should be determined by extensive IHC using multiple sections in the multi-institutional cohorts in the future.

\section{Conclusions}

In conclusion, our study showed that positive PD-L1 expression independently predicts poor response to chemoradiotherapy and worse survival of patients with ESCC receiving neoadjuvant chemoradiotherapy followed by esophagectomy. Therefore, PD-L1 might be a potential target in advanced ESCC patients receiving chemoradiotherapy.

Author Contributions: Conceptualization: S.-H.L.; Methodology: W.-T.H., Y.-C.L., L.-H.T., and S.-H.L.; Software: Y.-M.W., Y.-H.C., C.-M.L., and W.-C.L.; Validation: W.-T.H., H.-I.L., and S.-H.L.; Formal Analysis: H.-I.L., W.-C.L., and S.-H.L.; Investigation: S.-H.L.; Resources: W.-T.H., H.-I.L., Y.-M.W., Y.-H.C., C.-M.L., and S.-H.L.; Data Curation: W.-T.H., H.-I.L., Y.-M.W., Y.-H.C., C.-M.L., W.-C.L., Y.-C.L., L.-H.T., and S.-H.L.; Writing-Original Draft Preparation: W.-T.H. and S.-H.L.; Writing—Review and Editing: S.-H.L.; Supervision: S.-H.L.; Funding Acquisition: S.-H.L.; All authors read and approved the final manuscript.

Funding: This work was supported in part by grants from the National Science Council, Taiwan (MOST 106-2314 -B-182A-159-MY3 and MOST 107-2314-B-182A-156-MY3), and Chang Gung Memorial Hospital (CMRPG8J0401, CMRPG8G0892, CMRPG8I0201, and CMRPG8J1061).

Acknowledgments: We would also like to thank Chang Gung Medical Foundation Kaohsiung Chang Gung Memorial Hospital Biobank and Tissue Bank Core Laboratory (CLRPG8F1701 and CLRPG8F1602) for excellent technical support.

Conflicts of Interest: The authors report no conflicts of interest. The authors alone are responsible for the content and writing of this article. 


\section{References}

1. Bray, F.; Ferlay, J.; Soerjomataram, I.; Siegel, R.L.; Torre, L.A.; Jemal, A. Global cancer statistics 2018: Globocan estimates of incidence and mortality worldwide for 36 cancers in 185 countries. CA Cancer J. Clin. 2018, 68, 394-424. [CrossRef] [PubMed]

2. Li, S.H.; Chen, C.H.; Lu, H.I.; Huang, W.T.; Tien, W.Y.; Lan, Y.C.; Lee, C.C.; Chen, Y.H.; Huang, H.Y.; Chang, A.Y.; et al. Phosphorylated p70S6K expression is an independent prognosticator for patients with esophageal squamous cell carcinoma. Surgery 2015, 157, 570-580. [CrossRef] [PubMed]

3. Li, S.H.; Lu, H.I.; Chang, A.Y.; Huang, W.T.; Lin, W.C.; Lee, C.C.; Tien, W.Y.; Lan, Y.C.; Tsai, H.T.; Chen, C.H. Angiotensin II type I receptor (AT1R) is an independent prognosticator of esophageal squamous cell carcinoma and promotes cells proliferation via mTOR activation. Oncotarget 2016, 7, 67150-67165. [CrossRef] [PubMed]

4. Sherman, C.A.; Turrisi, A.T.; Wallace, M.B.; Reed, C.E. Locally advanced esophageal cancer. Curr. Treat. Options Oncol. 2002, 3, 475-485. [CrossRef] [PubMed]

5. Van der Werf, L.R.; Dikken, J.L.; van Berge Henegouwen, M.I.; Lemmens, V.; Nieuwenhuijzen, G.A.P.; Wijnhoven, B.P.L.; Dutch Upper GI Cancer Audit Group. A Population-based Study on Lymph Node Retrieval in Patients with Esophageal Cancer: Results from the Dutch Upper Gastrointestinal Cancer Audit. Ann. Surg. Oncol. 2018, 25, 1211-1220. [CrossRef] [PubMed]

6. Lu, H.I.; Li, S.H.; Huang, W.T.; Rau, K.M.; Fang, F.M.; Wang, Y.M.; Lin, W.C.; Tien, W.Y. A comparative study of isolated and metachronous oesophageal squamous cell carcinoma with antecedent upper aerodigestive tract cancer. Eur. J. Cardiothorac. Surg. 2013, 44, 860-865. [CrossRef]

7. Bedenne, L.; Michel, P.; Bouche, O.; Milan, C.; Mariette, C.; Conroy, T.; Pezet, D.; Roullet, B.; Seitz, J.F.; Herr, J.P.; et al. Chemoradiation followed by surgery compared with chemoradiation alone in squamous cancer of the esophagus: FFCD 9102. J. Clin. Oncol. 2007, 25, 1160-1168. [CrossRef]

8. Toxopeus, E.; van der Schaaf, M.; van Lanschot, J.; Lagergren, J.; Lagergren, P.; van der Gaast, A.; Wijnhoven, B. Outcome of Patients Treated Within and Outside a Randomized Clinical Trial on Neoadjuvant Chemoradiotherapy Plus Surgery for Esophageal Cancer: Extrapolation of a Randomized Clinical Trial (CROSS). Ann. Surg. Oncol. 2018, 25, 2441-2448. [CrossRef]

9. Nygaard, K.; Hagen, S.; Hansen, H.S.; Hatlevoll, R.; Hultborn, R.; Jakobsen, A.; Mantyla, M.; Modig, H.; Munck-Wikland, E.; Rosengren, B.; et al. Pre-operative radiotherapy prolongs survival in operable esophageal carcinoma: A randomized, multicenter study of pre-operative radiotherapy and chemotherapy. The second Scandinavian trial in esophageal cancer. World J. Surg. 1992, 16, 1104-1109. [CrossRef]

10. Gebski, V.; Burmeister, B.; Smithers, B.M.; Foo, K.; Zalcberg, J.; Simes, J. Survival benefits from neoadjuvant chemoradiotherapy or chemotherapy in oesophageal carcinoma: A meta-analysis. Lancet Oncol. 2007, 8, 226-234. [CrossRef]

11. Donington, J.S.; Miller, D.L.; Allen, M.S.; Deschamps, C.; Nichols, F.C., III; Pairolero, P.C. Tumor response to induction chemoradiation: Influence on survival after esophagectomy. Eur. J. Cardiothorac. Surg. 2003, 24, 631-636. [CrossRef]

12. Jones, D.R.; Detterbeck, F.C.; Egan, T.M.; Parker, L.A., Jr.; Bernard, S.A.; Tepper, J.E. Induction chemoradiotherapy followed by esophagectomy in patients with carcinoma of the esophagus. Ann. Thorac. Surg. 1997, 64, 185-191. [CrossRef]

13. Stahl, M.; Stuschke, M.; Lehmann, N.; Meyer, H.J.; Walz, M.K.; Seeber, S.; Klump, B.; Budach, W.; Teichmann, R.; Schmitt, M.; et al. Chemoradiation with and without surgery in patients with locally advanced squamous cell carcinoma of the esophagus. J. Clin. Oncol. 2005, 23, 2310-2317. [CrossRef] [PubMed]

14. Li, S.H.; Huang, E.Y.; Lu, H.I.; Huang, W.T.; Yen, C.C.; Huang, W.C.; Chen, C.H. Phosphorylated mammalian target of rapamycin expression is associated with the response to chemoradiotherapy in patients with esophageal squamous cell carcinoma. J. Thorac. Cardiovasc. Surg. 2012, 144, 1352-1359. [CrossRef] [PubMed]

15. Steyerberg, E.W.; Neville, B.A.; Koppert, L.B.; Lemmens, V.E.; Tilanus, H.W.; Coebergh, J.W.; Weeks, J.C.; Earle, C.C. Surgical mortality in patients with esophageal cancer: Development and validation of a simple risk score. J. Clin. Oncol. 2006, 24, 4277-4284. [CrossRef]

16. Butte, M.J.; Keir, M.E.; Phamduy, T.B.; Sharpe, A.H.; Freeman, G.J. Programmed death-1 ligand 1 interacts specifically with the B7-1 costimulatory molecule to inhibit T cell responses. Immunity 2007, 27, 111-122. [CrossRef] 
17. Dong, H.; Zhu, G.; Tamada, K.; Chen, L. B7-H1, a third member of the B7 family, co-stimulates T-cell proliferation and interleukin-10 secretion. Nat. Med. 1999, 5, 1365-1369. [CrossRef]

18. Ceeraz, S.; Nowak, E.C.; Noelle, R.J. B7 family checkpoint regulators in immune regulation and disease. Trends Immunol. 2013, 34, 556-563. [CrossRef]

19. Ritprajak, P.; Azuma, M. Intrinsic and extrinsic control of expression of the immunoregulatory molecule PD-L1 in epithelial cells and squamous cell carcinoma. Oral Oncol. 2015, 51, 221-228. [CrossRef]

20. Pilones, K.A.; Vanpouille-Box, C.; Demaria, S. Combination of radiotherapy and immune checkpoint inhibitors. Semin. Radiat. Oncol. 2015, 25, 28-33. [CrossRef]

21. Afreen, S.; Dermime, S. The immunoinhibitory B7-H1 molecule as a potential target in cancer: Killing many birds with one stone. Hematol. Oncol. Stem Cell Ther. 2014, 7, 1-17. [CrossRef] [PubMed]

22. Brahmer, J.R.; Tykodi, S.S.; Chow, L.Q.; Hwu, W.J.; Topalian, S.L.; Hwu, P.; Drake, C.G.; Camacho, L.H.; Kauh, J.; Odunsi, K.; et al. Safety and activity of anti-PD-L1 antibody in patients with advanced cancer. N. Engl. J. Med. 2012, 366, 2455-2465. [CrossRef] [PubMed]

23. Topalian, S.L.; Hodi, F.S.; Brahmer, J.R.; Gettinger, S.N.; Smith, D.C.; McDermott, D.F.; Powderly, J.D.; Carvajal, R.D.; Sosman, J.A.; Atkins, M.B.; et al. Safety, activity, and immune correlates of anti-PD-1 antibody in cancer. N. Engl. J. Med. 2012, 366, 2443-2454. [CrossRef] [PubMed]

24. Kojima, T.; Doi, T. Immunotherapy for Esophageal Squamous Cell Carcinoma. Curr. Oncol. Rep. 2017, 19, 33. [CrossRef]

25. Kudo, T.; Hamamoto, Y.; Kato, K.; Ura, T.; Kojima, T.; Tsushima, T.; Hironaka, S.; Hara, H.; Satoh, T.; Iwasa, S.; et al. Nivolumab treatment for oesophageal squamous-cell carcinoma: An open-label, multicentre, phase 2 trial. Lancet Oncol. 2017, 18, 631-639. [CrossRef]

26. Sznol, M.; Chen, L. Antagonist antibodies to PD-1 and B7-H1 (PD-L1) in the treatment of advanced human cancer. Clin. Cancer Res. 2013, 19, 1021-1034. [CrossRef]

27. Chiu, T.J.; Lu, H.I.; Chen, C.H.; Huang, W.T.; Wang, Y.M.; Lin, W.C.; Li, S.H. Osteopontin Expression Is Associated with the Poor Prognosis in Patients with Locally Advanced Esophageal Squamous Cell Carcinoma Receiving Preoperative Chemoradiotherapy. BioMed. Res. Int. 2018, 2018, 9098215. [CrossRef]

28. Wang, Q.; Liu, F.; Liu, L. Prognostic significance of PD-L1 in solid tumor: An updated meta-analysis. Medicine 2017, 96, 6369. [CrossRef]

29. Hatogai, K.; Fujii, S.; Kojima, T.; Daiko, H.; Nomura, S.; Doi, T.; Kitano, S.; Ohtsu, A.; Takiguchi, Y.; Yoshino, T.; et al. Large-scale comprehensive immunohistochemical biomarker analyses in esophageal squamous cell carcinoma. J. Cancer Res. Clin. Oncol. 2017, 143, 2351-2361. [CrossRef]

30. Qu, H.X.; Zhao, L.P.; Zhan, S.H.; Geng, C.X.; Xu, L.; Xin, Y.N.; Jiang, X.J. Clinicopathological and prognostic significance of programmed cell death ligand 1 (PD-L1) expression in patients with esophageal squamous cell carcinoma: A meta-analysis. J. Thorac. Dis. 2016, 8, 3197-3204. [CrossRef]

31. Tamaoki, M.; Komatsuzaki, R.; Komatsu, M.; Minashi, K.; Aoyagi, K.; Nishimura, T.; Chiwaki, F.; Hiroki, T.; Daiko, H.; Morishita, K.; et al. Multiple roles of single-minded 2 in esophageal squamous cell carcinoma and its clinical implications. Cancer Sci. 2018, 109, 1121-1134. [CrossRef] [PubMed]

32. Tanaka, Y.; Aoyagi, K.; Minashi, K.; Komatsuzaki, R.; Komatsu, M.; Chiwaki, F.; Tamaoki, M.; Nishimura, T.; Takahashi, N.; Oda, I.; et al. Discovery of a Good Responder Subtype of Esophageal Squamous Cell Carcinoma with Cytotoxic T-Lymphocyte Signatures Activated by Chemoradiotherapy. PLoS ONE 2015, 10, e0143804. [CrossRef] [PubMed]

33. Lim, S.H.; Hong, M.; Ahn, S.; Choi, Y.L.; Kim, K.M.; Oh, D.; Ahn, Y.C.; Jung, S.H.; Ahn, M.J.; Park, K.; et al. Changes in tumour expression of programmed death-ligand 1 after neoadjuvant concurrent chemoradiotherapy in patients with squamous oesophageal cancer. Eur. J. Cancer 2016, 52, 1-9. [CrossRef] [PubMed]

34. Antonia, S.J.; Villegas, A.; Daniel, D.; Vicente, D.; Murakami, S.; Hui, R.; Yokoi, T.; Chiappori, A.; Lee, K.H.; de Wit, M.; et al. Durvalumab after Chemoradiotherapy in Stage III Non-Small-Cell Lung Cancer. N. Engl. J. Med. 2017, 377, 1919-1929. [CrossRef]

(C) 2019 by the authors. Licensee MDPI, Basel, Switzerland. This article is an open access article distributed under the terms and conditions of the Creative Commons Attribution (CC BY) license (http://creativecommons.org/licenses/by/4.0/). 